ADLFI. Archéologie de la France -

INFORMATIONS

Informations

une revue Gallia

Aquitaine | 2009

\title{
Entre-Deux-Mers
}

\section{Damien Baron}

\section{CpenEdition \\ Journals}

Édition électronique

URL : http://journals.openedition.org/adlfi/4106

ISSN : 2114-0502

Éditeur

Ministère de la culture

Référence électronique

Damien Baron, «Entre-Deux-Mers », ADLFI. Archéologie de la France - Informations [En ligne], Aquitaine, mis en ligne le 01 mars 2009, consulté le 26 avril 2019. URL : http://journals.openedition.org/ adlfi/4106

Ce document a été généré automatiquement le 26 avril 2019

(c) Ministère de la Culture et de la Communication, CNRS 


\title{
Entre-Deux-Mers
}

\author{
Damien Baron
}

Identifiant de l'opération archéologique : 0225516

Date de l'opération : 2009 (PR)

1 Deux campagnes de prospection pédestre diachronique ont été réalisées au cœur de l'Entre-Deux-Mers dans le canton de Targon, sur les communes de Cessac, Courpiac et Bellefond, le long du ruisseau de l'Engranne.

2 Menées entre le printemps et l'automne 2009 dans le cadre d'un mémoire de Master II Archéologie, elles sont venues s'insérer dans l'étude de l'occupation du sol de cette même zone de la Préhistoire à la fin de l'Antiquité.

3 Ces prospections systématiques, ont livré un mobilier abondant et diversifié, parmi lequel 631 éléments ont pu être analysés et datés. Si la céramique commune domine l'ensemble, la nature des vestiges traduit elle aussi cette variété : outils paléolithiques et néolithiques, fragments d'amphore, de tegulae,ainsi qu'une probable meule d'époque gallo-romaine, une hypothétique cuillère à fard en bronze ou un instrument de chirurgie de même époque, et des monnaies de cuivre modernes. La chronologie s'étend ainsi du Paléolithique moyen, voire ancien, jusqu'à la fin de l'époque moderne, avec une certaine rareté d'indices antiques et une absence quasi-certaine d'éléments du Haut Moyen Âge.

Quelques concentrations de mobilier ou ensembles cohérents ont été repérés à l'échelle d'une parcelle ou d'un champ, dans la plaine alluvionnaire de l'Engranne et ses abords immédiats. Ils se répartissent entre le Moyen Âge (XII ${ }^{e}$ s.-XIII ${ }^{e}$ s. puis XIV ${ }^{e}$ s.-XV ${ }^{e}$ s.) et l'époque moderne (XVI $\mathrm{e}$ s.-XVII ${ }^{\mathrm{e}} \mathrm{s}$.).

D'autre part, trois indices de sites sont à envisager, eux aussi au voisinage du ruisseau. Le premier se résume à de fines traces protohistoriques entre Courpiac et Bellefond (deux bords ainsi qu'un fragment de Dressel 1 attribués à la fin du second âge du Fer), qui constituent à ce jour les seuls éléments connus d'une présence gauloise dans ces communes. Nous y supposons l'emplacement d'une petite ferme de la fin du second âge 
du Fer ou du début de l'époque gallo-romaine. Un second site semble se dessiner au lieudit "Tertre de la Bertouse " à Courpiac, à proximité d'une motte médiévale où un mobilier très fourni des XIII ${ }^{\mathrm{e}} \mathrm{s}$.-XV $\mathrm{s}$. a été ramassé. Enfin, à l'est du «hameau de la Goilane » à Bellefond, la cohérence du matériel (XVI ${ }^{e} \mathrm{~s}$-XVII $\mathrm{s}$. avec peut-être des éléments plus précoces) laisse entrevoir une probable petite ferme d'époque moderne.

\section{INDEX}

operation Prospection (PR)

Index chronologique : âge du Fer, Antiquité romaine, Empire romain, Moyen Âge, Néolithique, Paléolithique, Préhistoire, Temps Modernes

Thèmes : amphore, amphore gauloise, céramique commune, ferme, meule, mobilier, occupation du sol, outil, tuile

Index géographique : Aquitaine, Gironde (33), Targon, Cessac, Courpiac, Bellefond

\section{AUTEURS}

DAMIEN BARON

SUP 